\title{
Responses of Leaf Photosynthesis, Plant Growth and Fruit Production to Periodic Alteration of Plant Density in Winter Produced Single-truss Tomatoes
}

\author{
Chengyao Jiang ${ }^{1}$, Masahumi Johkan ${ }^{1 *}$, Masaaki Hohjo ${ }^{2}$, Satoru Tsukagoshi², \\ Mitsuru Ebihara ${ }^{3 * *}$, Akio Nakaminami ${ }^{3}$ and Toru Maruo ${ }^{1}$ \\ ${ }^{1}$ Graduate School of Horticulture, Chiba University, Matsudo 271-8510, Japan \\ ${ }^{2}$ Center for Environment, Health and Field Sciences, Chiba University, Kashiwa 277-0882, Japan \\ ${ }^{3}$ Mitsubishi Plastic Agri Dream Co., LTD, Tsukubamirai 300-2435, Japan
}

Tomato plants in greenhouse production are often confronted with light insufficiency in the lower canopy, especially in the winter low irradiation season. In this study, periodic alteration of plant density (PD) was proposed to improve the light environment of plants' lower canopies, leaf photosynthesis, plant growth, and fruit development. These were investigated with winter cultivated tomatoes in a single-truss production system. Seedlings were transplanted to either movable or fixed cultivation benches for treatments with fixed PDs of 14.3 plants $\cdot \mathrm{m}^{-2}$ (F14.3), and 10 plants $\cdot \mathrm{m}^{-2}$ (F10), and unfixed PDs in a movable bench (MB; 25 plants $\cdot \mathrm{m}^{-2}$ after transplanting to anthesis, 16.6 plants $\cdot \mathrm{m}^{-2}$ at anthesis to initial fruit set, 12.5 plants $\cdot \mathrm{m}^{-2}$ at fruit set to mature green, and 11.1 plants $\cdot \mathrm{m}^{-2}$ at mature green to red-ripe). The leaf photosynthesis rates in $\mathrm{MB}$ and F10 were generally significantly higher than in F14.3. F14.3 had the tallest stems, but the lowest leaf area and shoot dry weight at end of experiment, while MB and F10 were not significantly different. MB had significantly the highest total yield, while the lowest data were observed in F10. The soluble solids content was increased in MB and F10 compared with F14.3, but no significant differences in ascorbic acid content or fruit hardness were observed among treatments. Therefore, a high PD in the vegetative stage, but a relatively lower $P D$ in the fruit development stage, was highly efficient in intensive tomato cultivation.

Key Words: fruit fresh weight, light insufficiency, net photosynthetic rate, shading index, soluble solids.

\section{Introduction}

Traditional greenhouse tomato production is always labor intensive and has a long production period and variable yield (Fisher et al., 1990; Govindasamy, 1996; Kozai, 2005). To solve these problems, the single-truss tomato production system (STTPS), which has a shortened production cycle, uniform fruit, potential for automation, and labor saving, has been developed and drawn more and more attention worldwide (Giniger et al., 1988; Janes and McAvoy, 1989, 1991; Logendra and Janes, 1999; Ting et al., 1993). In Japan, the annual

Received; October 25, 2016. Accepted; February 9, 2017.

First Published Online in J-STAGE on April 18, 2017.

This work was supported by the State Scholarship Fund (China Scholarship Council) and Support Program for Young Researcher (AGSST, Chiba University).

* Corresponding author (Email: johkan@faculty.chiba-u.jp).

** Present address: Aeon Agri Creativity Co., LTD, Chiba 261-8515, Japan. average yield of tomatoes in STTPS can reach $36 \mathrm{~kg}$. $\mathrm{m}^{-2}$ at a plant density (PD) of 10 plants $\cdot \mathrm{m}^{-2}$, and it is hoped that this number will be enhanced at higher densities and with improved light use efficiency (Higashide and Heuvelink, 2009; Kobayashi, 1997, 1999).

As plants grow, there is inevitable mutual shading caused by branches and leaves, which leads to light deficiency in the lower canopy (Lu et al., 2012; Steinger et al., 2003). Previous research has shown that insufficient light causes both morphological and physiological changes in plants, such as an increase in specific leaf area and plant height, which maximizes the capture of available light to meet the demand for photosynthesis, but results in more drastic shading. Additionally, the competition for light within the canopy during intensive crop cultivation can trigger premature leaf senescence (Rousseaux et al., 1996; Steinger et al., 2003), which weakens the plants' reproductive ability, leading to yield decreases. This situation is exacerbated in the STTPS because the PD is much higher than in common 
commercial tomato production, especially in the winter production period when solar light interception is limited in both upper and lower canopy leaves (Gunnlaugsson and Adalsteinsson, 2006). In the winter production period in the Tokyo region of Japan, from late November to early March, the daily integral amount of solar radiation is only $8.6-11.7 \mathrm{MJ} \cdot \mathrm{m}^{-2}$ (Japan Meteorological Agency, http://www.data.jma.go. $\mathrm{jp} / \mathrm{obd} / \mathrm{stats} / \mathrm{etrn} / \mathrm{view} / 3$ monthly_s1.php?prec_no $=44 \&$ block_no $=47662 \&$ year $=2015 \&$ month $=2 \&$ day $=\&$ view $=$ p7, October 25, 2016), and more than $40 \%$ of days will be cloudy, raining or snowy, making the irradiation conditions of the lower canopy worse. Therefore, it is important to improve the light environment in the lower canopy in STTPS to enhance the fruit yield.

Usually, cultivators use supplemental lighting to compensate for the shortage of lighting in lower leaves, which adds extra cost in terms of electricity consumption and equipment maintenance, unavoidably adding to production costs. However, plants before anthesis are often still short and have a small leaf area, so there is no mutual shading. This means the cultivation area at the immature plant stage in greenhouses includes wasted space in a fixed bench system because plant and bench distances are decided by the final plant size. These conflicting situations inspired us to develop a new STTPS in which young and mature tomato plants are cultivated together to realize space-saving and yield enhancement. In this system, we adopted movable cultivation benches to manipulate the PD by adjusting the bench distance to meet the light needs for plants at different development stages. We assumed that a high PD in the vegetative stage would not affect plant reproductive potential as long as the PD were alternated to a relatively lower level in the fruit development stage. However, a suitable PD to satisfy the physiological and reproductive needs for plant development at certain stages and maximize land usage needs to be determined. Therefore, the present experiment was carried out to investigate how tomato plant morphological and physiological characteristics respond to changes in PD at different growth stages, and identify suitable PD changes needed for optimal tomato development and reproduction.

\section{Materials and Methods}

\section{Plant material and growth conditions}

Tomatoes ('Momotaro York'; Takii Seed Co., Ltd., Kyoto, Japan) were cultivated hydroponically with a STTPS in a greenhouse in Kashiwa-no-ha, Kashiwa,

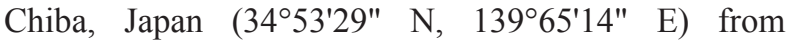
November 2014 to March 2015. Seeds were sown in plug trays filled with a commercial substrate (Best Mix; Nippon Rockwool Co., Tokyo, Japan) on November 1, 2014 and germinated in darkness for 3 days, then grown in a temperature-controlled chamber equipped with fluorescent tubes (Nae Terrace; MKV Dream Co., Ltd., Tsukubamirai, Japan) for 21 days. The chamber was op- erated at a photosynthetic photon flux density (PPFD) of $350 \mu \mathrm{mol} \cdot \mathrm{m}^{-2} \cdot \mathrm{s}^{-1}$, a $16-\mathrm{h}$ photoperiod, $23 / 18^{\circ} \mathrm{C}$ day $/$ night temperatures, and an $800 \mu \mathrm{mol} \cdot \mathrm{mol}^{-1} \mathrm{CO}_{2}$ concentration. The trays were sub-irrigated every other day with a commercial nutrient solution at an electrical conductivity (EC) of $1.5 \mathrm{dS} \cdot \mathrm{m}^{-1}$.

On the 24 day after sowing, the seedlings were transplanted to foam block cultivation benches in the greenhouse (Fig. 1). A drip irrigation nutrient solution (Nakano et al., 2010) adjusted to $1.8 \mathrm{dS} \cdot \mathrm{m}^{-1} \mathrm{EC}$ was automatically supplied with a feeding rate of $100-120 \mathrm{~mL}$ per irrigation event per plant from 06:00 until 18:00. The EC of the nutrient solution was gradually increased from 1.8 to $6.5 \mathrm{dS} \cdot \mathrm{m}^{-1}$ depending on plant growth and development. Three leaves were left under the fruit truss from anthesis, the first top pinching was performed on the 35 day after transplanting, and three leaves were left above the fruit truss. Other maintenance, including pruning of lower leaves and removal of side shoots, was performed weekly and a 4chlorophenoxy acetate-containing solution (Tomato Tone; ISK Biosciences K.K., Tokyo, Japan) was sprayed on completely blooming flowers from which the five most productive fruits were selected for future fruit production. The variation in thermal environment factors is shown in Figure 2. During the experiment, inside greenhouse the daily integral amount of solar radi-
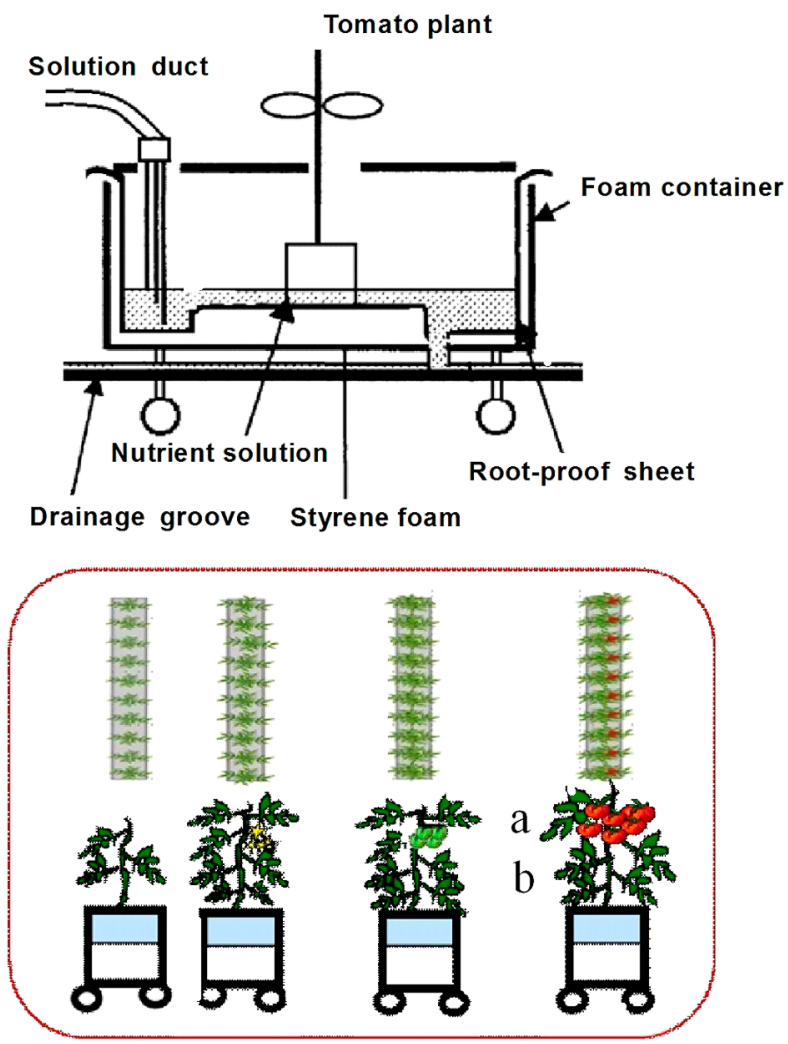

Fig. 1. Schematic diagram of the movable bench system. Bench shading index $=1-\mathrm{b} / \mathrm{a}$, both side light irradiation checks were carried out every day at 10:00, 12:00, 14:00, and 16:00. 

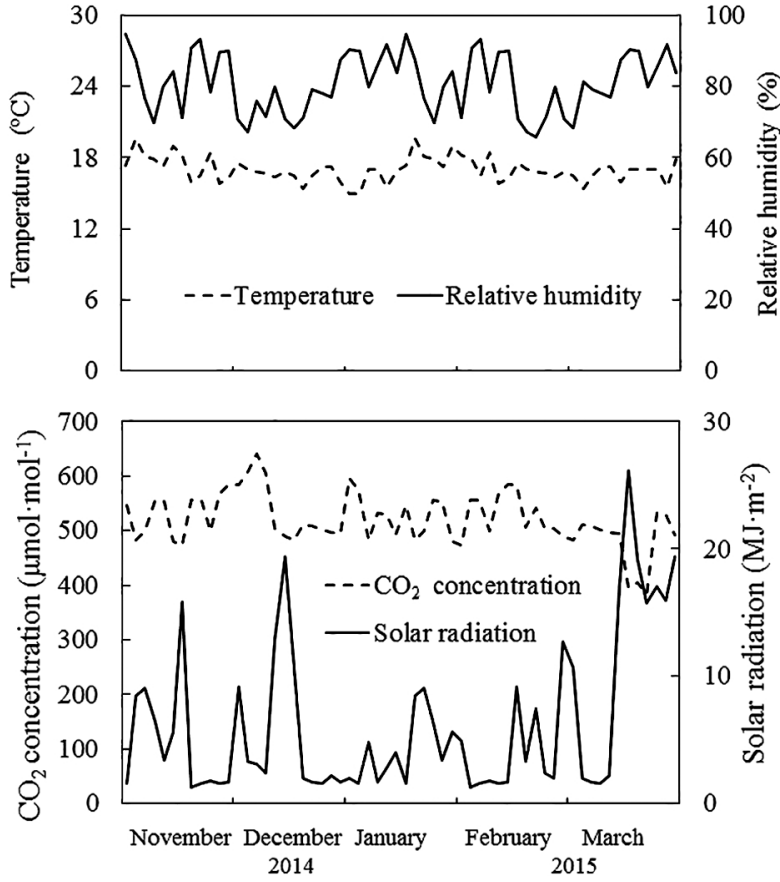

Fig. 2. The variation in daily mean air temperature, relative humidity, $\mathrm{CO}_{2}$ concentration, and integral amount of solar radiation inside the greenhouse from November, 2014 to March, 2015.

ation was varied from $1.06-26.1 \mathrm{MJ} \cdot \mathrm{m}^{-2}$ (December to March), and air conditioners were used to maintain the thermal environment, making the average daily air temperature around $15-20^{\circ} \mathrm{C}$, while the daily mean relative humidity was maintained above $60 \%$, and the $\mathrm{CO}_{2}$ concentration was 384-604 $\mu \mathrm{mol} \cdot \mathrm{mol}^{-1}$.

\section{PD treatment}

Seedlings were transplanted into foam containers on a cultivation bench. In each row of benches, the plant distance was fixed at $0.1 \mathrm{~m}$ according to commercial production routine. Two fixed bench distances were set as controls, with row distances of 0.7 and $1.0 \mathrm{~m}$, which gave PDs of 14.3 plants $\cdot \mathrm{m}^{-2}$ (Lu et al., 2012) and 10 plants $\cdot \mathrm{m}^{-2}$ (Kobayashi, 1997, 1999), respectively (abbreviated as F14.3 and F10).

In the movable bench group (MB) (Fig. 1), the bench distance was adjusted to minimize shading between rows. Previous studies were usually concerned about the light interception extent (light received by the lower canopy/light received by the upper canopy), not mutual shading extent. In this study, to identify the light irradiation loss caused by mutual shading among rows of plants at a certain bench distance, we defined the bench shading index and calculated it as 1-(light intensity received by the second leaf under the fruit)/(light intensity received by the first leaf above the fruit). Integrated solar radiation on the leaf surfaces was measured with Quantum Sensors (SQ/MQ-200; Apogee Instruments, Logan, UT, USA).

According to previous research, we divided the plant development period into four stages ( $\mathrm{Lu}$ et al., 2012; McAvoy et al., 1989): Stage 1, after transplanting to anthesis, 21 days; Stage 2, anthesis to initial fruit set, 21 days; Stage 3, fruit set to mature green, 42 days; Stage 4, mature green to red-ripe, 14 days. Previous research has reported that when applied with supplemental lighting, the light irradiated on the lower canopy could reach $60 \%$ compared with the amount irradiated on the upper canopy (calculated according to Lu et al., 2012). Therefore in this study, we adjusted the PD to obtain a shading index around $40 \%$ to guarantee nearly $60 \%$ of light could reach the lower canopy, which meant the row distances were $0.4 \mathrm{~m}$ (Stage 1), $0.6 \mathrm{~m}$ (Stage 2), $0.8 \mathrm{~m}$ (Stage 3), and $0.9 \mathrm{~m}$ (Stage 4), with corresponding PDs of $25,16.6,12.5$, and 11.1 plants $\cdot \mathrm{m}^{-2}$.

\section{Leaf gas-exchange measurements}

Leaf gas-exchange measurements were made on the third fully mature leaflets of leaves both above and under the fruit truss essentially as described in the work of Matsuda et al. (2014), using a portable gas-exchange measurement system (LI-6400; LI-COR Inc., Lincoln, NE, USA) between 9:00 and $14: 00$ on the $21,42,84$, and 98 days after transplanting. A light photosynthesis curve was made to determine the response of the net photosynthetic rate (NPR) to PPFD, and the measurement was conducted with a leaf temperature setting of $25 \pm 1{ }^{\circ} \mathrm{C}$, ambient $\mathrm{CO}_{2}$ concentration setting of $370 \pm 10 \mu \mathrm{mol} \cdot \mathrm{m}^{-2}$, relative humidity setting of $60 \pm 2 \%$, leaf-to-air vapor pressure deficit setting of $1.1 \pm 0.1 \mathrm{kPa}$, and PPFD settings of $1500,1200,1000$, $800,600,400,200$, and $0 \mu \mathrm{mol} \cdot \mathrm{m}^{-2} \cdot \mathrm{s}^{-1}$. The actual NPR of the leaf under growth conditions was measured in the same position of leaves with the actual PPFD of each treatment and the same setting of leaf temperature, ambient $\mathrm{CO}_{2}$ concentration, relative humidity, and leafto-air vapor pressure deficit as shown above.

\section{Plant growth and development analyses}

The lengths and diameters of stems were measured every 7 days after transplanting and the rates of stem elongation (SER) and stem diameter enlargement (DER) of each plant were calculated as the slopes of the first-order regression equations for time courses of stem length and diameter, respectively. On the $21,42,84$, and 98 days after transplanting, the leaf area was also measured to calculate the leaf area index (LAI, leaf area/total area) on the same plant for which SER and DER were measured, with an area meter (LI-3000C; LI-COR Inc.). After fruit harvest, plants from each group were randomly selected for destructive harvesting. Each plant shoot was divided into leaves and stem parts. After total leaf areas were measured, the materials were oven dried at $100^{\circ} \mathrm{C}$ for $1 \mathrm{~h}$ followed by $80^{\circ} \mathrm{C}$ for 3 days to measure dry weight. The roots were not subjected to measurements because of the difficulty of retrieving them from the substrate. 


\section{Fruit yield and quality analyses}

The fruit was harvested from the 99 day after transplanting, and fruit diameter, and fresh and dry weight were measured. The soluble solids content of tomato fruit was determined using a refractometer (PAL-1; Atago Co., Ltd., Tokyo, Japan), ascorbic acid content was determined with a RQ Flex plus (Merck Co., Ltd., Darnstadt, Germany), and fruit hardness was determined with a fruit hardness tester (FR-5120; Lutron Electronic Enterprise Co., Ltd., Taipei, Taiwan). Fruits were collected for fruit diameter and fresh weight determination and the relationship between them using a regression equation as follows: $\mathrm{y}=0.0588 \mathrm{x}^{2}-$ $1.7325 \mathrm{x}-13.444$, with $R^{2}=0.9918 \quad(\mathrm{y}=$ fruit fresh weight and $\mathrm{x}=$ fruit diameter). The fruit diameter of each group was measured every 7 days from the fruit sizing stage to harvest, and the fruit fresh weight in each stage was estimated using the equation above.

\section{Statistical analyses}

Statistical software (SPSS 11.0; SPSS Inc., Chicago, USA) was used for data analysis. Mean separations were conducted using a Tukey's HSD test protected by ANOVA (Analysis of Variance) at $P<0.05$.

\section{Results}

\section{Light conditions for plants in different treatments}

Obvious shading occurred as the tomato plants grew (Fig. 3). In the vegetative stages (Stages 1 and 2), the shading index was maintained below $45 \%$ in all three treatments. However, the shading index in the F14.3 treatment drastically increased to $68.7 \%$ in Stage 3 and $70.4 \%$ at harvest time. There was a slight but steady increase trend in both the F10 and MB treatments, but the shading index was kept below $43 \%$ most of the time. However, F10 showed an obvious increase at Stage 4.

\section{Leaf photosynthesis characteristics}

The light response curve of leaves assessed the leaf photosynthetic capacity in different treatments at each stage (Fig. 4A-D). Under low light irradiation (PPFD

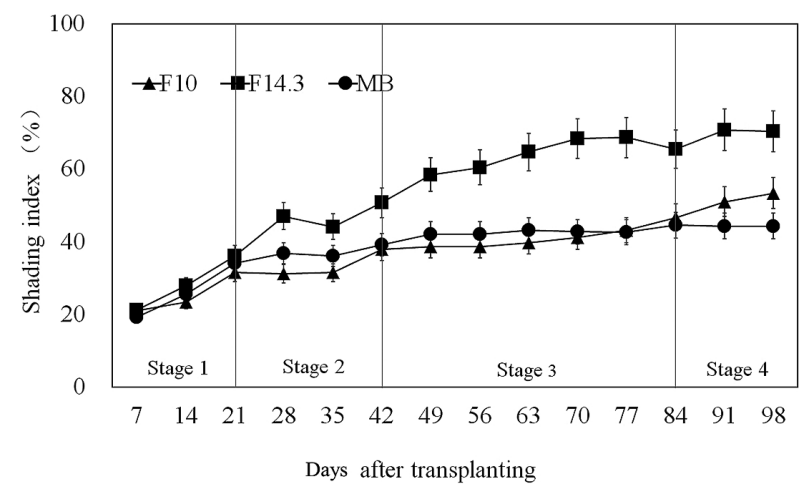

Fig. 3. Changes in the shading index with fixed and movable bench treatments in a single-truss tomato production system. Vertical bars represent standard errors of the means $(n=12)$.
$<400 \mu \mathrm{mol} \cdot \mathrm{m}^{-2} \cdot \mathrm{s}^{-1}$ ), NPR (the net photosynthetic rate at a certain PPFD) was almost the same in all treatments. However, as the light intensity increased, differences in NPR were observed. In Stage 1 (Fig. 4A), the NPR was highest in F10 (PPFD $=1500)$, and was $1.9 \%$ and 6\% higher than in F14.3 and MB, respectively. From Stage 2 (Fig. 4B), the NPR values of MB and F10 approached and then became obviously higher than that of F14.3. This phenomenon was significant in Stages 3 and 4 (Fig. 4C, D). The actual NPRs in all three treatments at Stages 3 and 4 were higher than in the previous two stages (Fig. 4E). In each stage, among the three treatments, NPR in F10 was higher than data in the other two treatments, and data in F14.3 was lowest, while MB was in the middle throughout the whole production period, but was close to F10.

\section{Whole plant growth and development}

The final stem diameter, total leaf area, and shoot DW were significantly lower in F14.3 (Table 1), although the plants in this treatment presented a significantly higher stem height. There were no significant differences in these indexes between F10 and MB. Table 2 shows the results of growth analysis. There was a peak of plant morphology development at Stage 1, and the speed obviously declined after that, considering the variation trends of SER and DER. Except for Stages 1, F14.3 presented the significantly largest SER, while F10 and MB presented a similarly lower SER after Stage 2. There was no significant difference in DER among treatments in Stages 1 and 2. However, data in F10 were significantly larger than the other two treatments in Stages 3 and 4. The correlation coefficients of these indexes showed that SER was negatively correlated to DER, while overall, DER was positively correlated with LAI, and LAI was negatively correlated with SER, except for Stage 4 (Table 3).

\section{Tomato fruit development and yield}

The fruit weight increased the most in Stage 3 and the cumulative fresh weight of fruit was higher in MB and F10 than in F14.3, especially in Stage 4 (Fig. 5). In terms of the harvest yield of a single plant, fresh fruit weight in $\mathrm{MB}$ increased $13.2 \%$ and $2.4 \%$, and dry weight increased $13.4 \%$ and $1.7 \%$ compared with F14.3 and F10, respectively (Table 4). The differences between F14.3 and the other two treatments were significant. To calculate the total yield of the whole winter production period, we calculated the actual calculated plant density (ACPD) of MB instead of using the plant density of MB in Stage 4. Because plants were transplanted into the greenhouse and cultivated for 98 days, and $\mathrm{MB}$ was transplanted every 14 days because of the commercial annual production schedule, seven benches were included in the calculation (Fig. 6). In the bench distance arrangement described above, the final distance from the 1 to 7 bench was $4.3 \mathrm{~m}$. Forty plants 


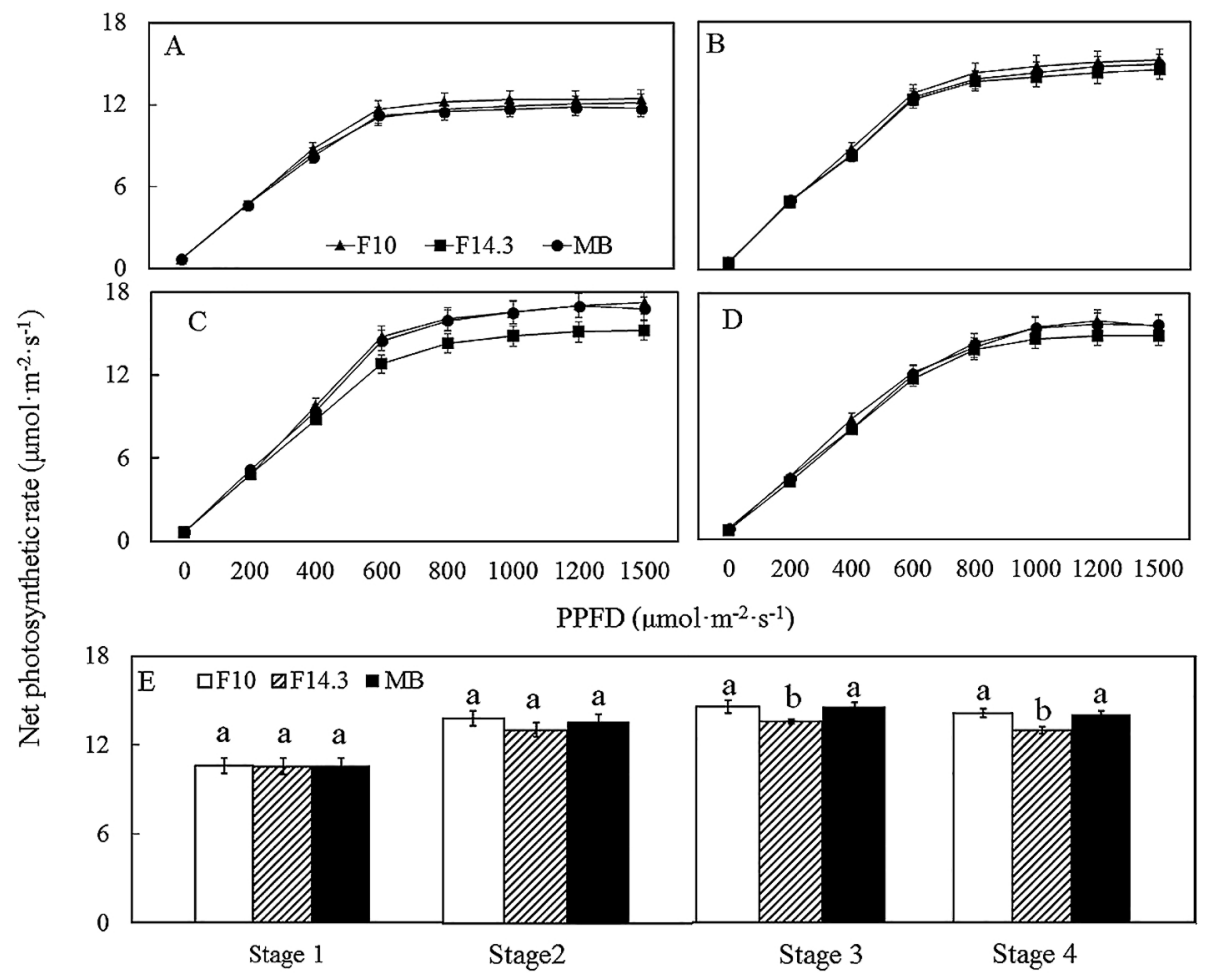

Fig. 4. Effects of different plant density (PD) treatments on photosynthesis. Light response curves were measured at photosynthetic photon flux densities of $0,200,400,600,800,1000,1200$, and $1500 \mu \mathrm{mol} \cdot \mathrm{m}^{-2} \cdot \mathrm{s}^{-1}$ in leaves of tomato plants at different PDs at Stage 1 (A), Stage 2 (B), Stage 3 (C), and Stage 4 (D) and the actual net photosynthetic rate of each stage was determined under the growth condition (E). Vertical bars represent standard errors of the means $(\mathrm{n}=8-16)$. Different letters show significant differences according to Tukey's HSD at $P<0.05$.

Table 1. The final stem height, stem diameter, total leaf area, and shoot dry weight (DW) of plants with fixed and movable bench treatments in a single-truss tomato production system.

\begin{tabular}{ccccc}
\hline \hline Treatment & $\begin{array}{c}\text { Stem height } \\
(\mathrm{cm})\end{array}$ & $\begin{array}{c}\text { Stem diameter } \\
(\mathrm{mm})\end{array}$ & $\begin{array}{c}\text { Total leaf area } \\
\left(\mathrm{m}^{2}\right)\end{array}$ & $\begin{array}{c}\text { Shoot DW } \\
(\mathrm{g})\end{array}$ \\
\hline F10 & $118 \mathrm{~b}^{\mathrm{z}}$ & $14.8 \mathrm{a}$ & $0.57 \mathrm{a}$ & $52.2 \mathrm{a}$ \\
F14.3 & $124 \mathrm{a}$ & $13.4 \mathrm{~b}$ & $0.41 \mathrm{~b}$ & $50.8 \mathrm{~b}$ \\
MB & $117 \mathrm{~b}$ & $14.9 \mathrm{a}$ & $0.53 \mathrm{a}$ & $53.1 \mathrm{a}$ \\
\hline
\end{tabular}

${ }^{\mathrm{z}}$ Means $(\mathrm{n}=12)$ with different letters within each row are significantly different by Tukey's HSD test at $P<0.05$.

were cultivated on each bench with a length of $4 \mathrm{~m}$. Thus, the ACPD was 16.27 plants $\cdot \mathrm{m}^{-2}$ as a result of the calculation: $\quad(40$ plants $\times 7$ benches $) /(4.3 \mathrm{~m} \times 4 \mathrm{~m})$. Therefore, the total yield in MB was the highest, followed by F14.3 and F10, and the differences among the three treatments were significant. The soluble solids content in MB and F10 was significantly higher than in F14.3, while the ascorbic acid content and fruit hardness were not significantly different among the treatments.

\section{Discussion}

Previous research has shown that high PD aggravates mutual shading, causing severe light interception along the plant profile and leading to suppressed photosynthetic activity in the lower canopy, which consequently limits plant growth and yield (Heuvelink and Dorais, 2005; Okano et al., 2001). In this experiment, although the PDs in MB were obviously higher than those in F10 and F14.3 in Stage 1 and Stage 2, the actual net photosynthesis rates were not significantly different among treatments (Fig. 4). This result indicates that a higher PD in the vegetative stage would not cause a significant decrease in leaf photosynthetic capacity development. However, after fruit set, the drastically increased shading index in F14.3 (Fig. 3) led to a significantly lower photosynthetic rate in this treatment, while there was no significant difference in the photosynthetic rate between MB and F10 (Fig. 4). This indicates that the PD at least needs to be adjusted to 12.5 plant $\cdot \mathrm{m}^{-2}$ at the fruit development stage. According to the FvCB photosynthesis model of $\mathrm{C}_{3}$ plants (Farquhar and von Caemmerer, 1982; Farquhar et al., 1980; Sharkey, 1985; von Caemmerer, 2000), with a normal $\mathrm{CO}_{2}$ concentration, a reduced PPFD limits photosynthesis through lightharvesting and electron-transport capacities. This ex- 
plains why a relatively higher PD $\left(14.3\right.$ plant $\left.\cdot \mathrm{m}^{-2}\right)$ in the reproductive stage significantly affects leaf photosynthetic production. Generally, light interception increases drastically as LAI increases and caused plant growth limitation, leading to plant morphologic influ-

Table 2. The stem elongation rate (SER), diameter enlargement rate (DER), and leaf area index (LAI) of tomato plants.

\begin{tabular}{clccc}
\hline \hline $\begin{array}{c}\text { Growth } \\
\text { stage }\end{array}$ & Treatment & $\begin{array}{c}\text { SER } \\
\left(\mathrm{cm} \cdot \mathrm{day}^{-1}\right)\end{array}$ & $\begin{array}{c}\text { DER } \\
\left(\mathrm{mm} \cdot \mathrm{day}^{-1}\right)\end{array}$ & $\begin{array}{c}\text { LAI } \\
\left(\mathrm{m}^{2} \cdot \mathrm{m}^{-2}\right)\end{array}$ \\
\hline \multirow{3}{*}{ Stage 1 } & F10 & $3.17 \mathrm{a}^{\mathrm{z}}$ & $0.11 \mathrm{a}$ & $3.3 \mathrm{~b}$ \\
& F14.3 & $3.00 \mathrm{a}$ & $0.13 \mathrm{a}$ & $3.4 \mathrm{~b}$ \\
& MB & $2.46 \mathrm{~b}$ & $0.13 \mathrm{a}$ & $5.9 \mathrm{a}$ \\
\hline \multirow{5}{*}{ Stage 2 } & F10 & $1.13 \mathrm{~b}$ & $0.10 \mathrm{a}$ & $4.4 \mathrm{~b}$ \\
& F14.3 & $1.25 \mathrm{a}$ & $0.10 \mathrm{a}$ & $4.8 \mathrm{~b}$ \\
& MB & $1.16 \mathrm{~b}$ & $0.10 \mathrm{a}$ & $5.5 \mathrm{a}$ \\
\hline \multirow{5}{*}{ Stage 3 } & F10 & $0.11 \mathrm{~b}$ & $0.10 \mathrm{a}$ & $5.7 \mathrm{~b}$ \\
& F14.3 & $0.40 \mathrm{a}$ & $0.07 \mathrm{~b}$ & $5.9 \mathrm{a}$ \\
& MB & $0.26 \mathrm{~b}$ & $0.07 \mathrm{~b}$ & $5.6 \mathrm{~b}$ \\
\hline \multirow{5}{*}{ Stage 4 } & F10 & $0.04 \mathrm{~b}$ & $0.03 \mathrm{a}$ & $5.7 \mathrm{a}$ \\
& F14.3 & $0.14 \mathrm{a}$ & $0.01 \mathrm{~b}$ & $5.9 \mathrm{a}$ \\
\hline
\end{tabular}

${ }^{z}$ Means $(n=12)$, within the same stage, with different letters within each row are significantly different by Tukey's HSD test at $P<0.05$.

Table 3. The matrix of correlation coefficients $(r)$ among stem elongation rate (SER), diameter enlargement rate (DER), and leaf area index (LAI) of tomato plants at different stages.

\begin{tabular}{ccc}
\hline \hline & SER & DER \\
\hline Stage 1 & & \\
DER & $-0.68^{* z}$ & \\
LAI & $-0.97^{*}$ & 0.48 \\
Stage 2 & & \\
DER & -0.28 & $0.94^{*}$ \\
LAI & -0.58 & \\
Stage 3 & & \\
DER & $-0.87^{*}$ & 0.16 \\
LAI & $-0.61^{*}$ & \\
Stage 4 & & \\
DER & $-0.73^{*}$ & $-0.83^{*}$ \\
LAI & $0.98^{*}$ & \\
\hline
\end{tabular}

${ }^{z} r$ values are given for all plants and asterisk $\left(^{*}\right)$ means significantly different at $P<0.05$. ences such as excessive plant elongation (Heuvelink and Dorais, 2005). However, in the vegetative stage, the difference overall in SER and DER between MB and F10 was not significant (except for the SER in Stage 1), even with obvious LAI differences, indicating a higher PD in this stage does not cause excessive plant growth. Higashide and Heuvelink (2009) reported that LAI could determine plant development because LAI can influence the light distribution and leaf photosynthetic and respiration rate. However, this phenomenon differs from tomato cultivars and general cultivation conditions, and tomatoes could grow equally when light dis-

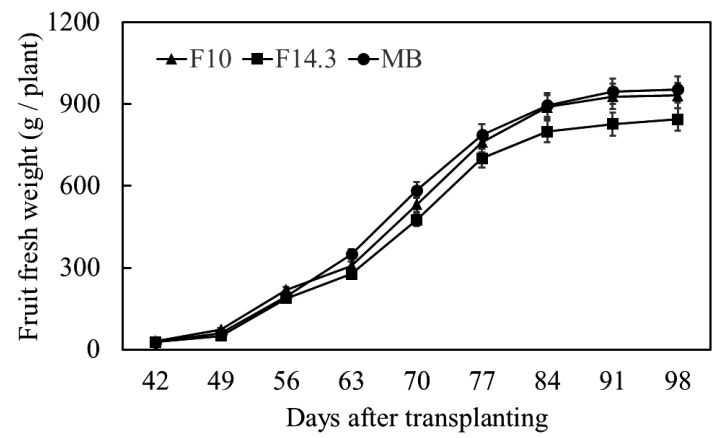

Fig. 5. The variation in cumulative fruit growth of tomato plants with different treatments. Vertical bars represent standard errors of the means $(n=12)$.

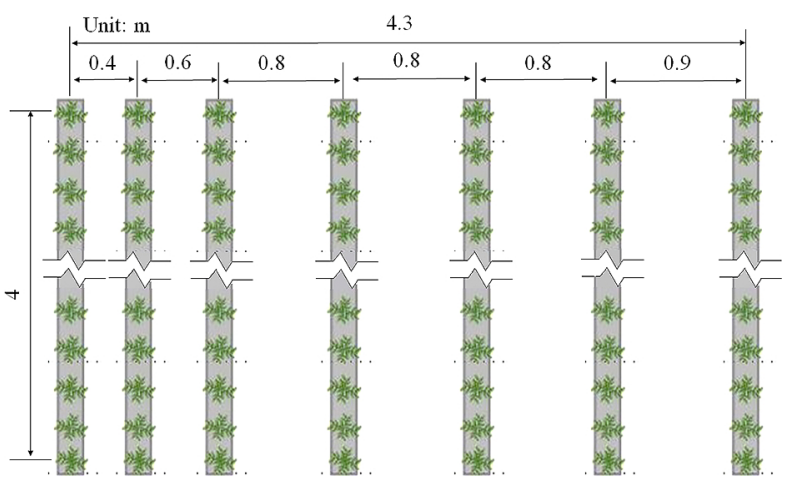

Fig. 6. Schematic diagram of the winter actual cultivation area used to calculate the actual calculated plant density (ACPD) in the movable bench system. Plants were transplanted every 14 days and the bench distance was adjusted according to the physiological stages described previously. There were seven benches and each bench contained 40 plants in the winter production period. Thus, the ACPD in MB for the total yield calculation was 16.27 plants $\cdot \mathrm{m}^{-2}$

Table 4. The fresh and dry yields of plants and tomato fruit quality with different treatments.

\begin{tabular}{ccccccc}
\hline \hline Treatment & $\begin{array}{c}\text { Fresh yield } \\
(\mathrm{g} / \text { plant })\end{array}$ & $\begin{array}{c}\text { Dry yield } \\
(\mathrm{g} / \mathrm{plant})\end{array}$ & $\begin{array}{c}\text { Total yield } \\
\left(\mathrm{kg} \cdot \mathrm{m}^{-2}\right)\end{array}$ & $\begin{array}{c}\text { Soluble solid content } \\
(\text { Bix\% })\end{array}$ & $\begin{array}{c}\text { Ascorbic acid content } \\
\left(\mathrm{mg} \cdot \mathrm{kg}^{-1} \mathrm{FW}\right)\end{array}$ & $\begin{array}{c}\text { Fruit hardness } \\
(\mathrm{kg} /[\mathrm{LB} \cdot \mathrm{Newton}])\end{array}$ \\
\hline F10 & $932 \mathrm{a}^{\mathrm{z}}$ & $35.8 \mathrm{a}$ & $9.32 \mathrm{c}$ & $6.7 \mathrm{~b}$ & $146 \mathrm{a}$ & $4.21 \mathrm{a}$ \\
F14.3 & $843 \mathrm{~b}$ & $32.1 \mathrm{~b}$ & $12.05 \mathrm{~b}$ & $5.3 \mathrm{c}$ & $143 \mathrm{a}$ & $4.13 \mathrm{a}$ \\
MB & $954 \mathrm{a}$ & $36.4 \mathrm{a}$ & $15.52^{\mathrm{y}} \mathrm{a}$ & $6.8 \mathrm{a}$ & $147 \mathrm{a}$ & $4.16 \mathrm{a}$ \\
\hline
\end{tabular}

${ }^{z}$ Means $(\mathrm{n}=12)$ with different letters within each row are significantly different by Tukey's HSD test at $P<0.05$.

$\mathrm{y}$ the total yield of MB was calculated as fresh yield $\times$ actual calculated plant density (the calculation shown in Fig. 6). 
tribution changes were accompanied by changes in PD and LAI (Gunnlaugsson and Adalsteinsson, 2006). In this study, the correlation coefficients between LAI and SER or LAI and DER were not strictly significant (Table 3). Also DER was not significantly different within MB and F10 in the vegetative stage (in which LAI was significantly different, Table 2), indicating that LAI was not the only limiting factor for plant morphological development.

Given the higher PD in vegetative stage does not cause a significant decrease in either leaf photosynthetic capacity or plant morphological growth, it should not affect the plant reproductive potential. Meanwhile, the MB treatment with relatively less shading had better light irradiation of the lower canopy in the reproductive stage (Fig. 3), and this improved light environment should lead to an enhancement in fruit yield (Hovi et al., 2004; McAvoy and Janes, 1988; Pettersen et al., 2010; Trouwborst et al., 2010). This hypothesis was confirmed by the significantly higher fruit development speed and both fresh and dry yield observed in MB, compared with F14.3 (Fig. 5; Table 4). Previous studies have reported that the tomato fruit assimilation rate is highest in Stage 3 and fruit is the highest priority for plant assimilate partitioning, this partition fraction increases until a steady-state occurs before harvest (Heuvelink and Dorais, 2005; Scholberg et al., 2000). With the lower PDs in MB and F10 after Stage 3, better light irradiation of the lower canopy (Fig. 3) and a higher leaf NPR was observed compared with F14.3 (Fig. 4). Since there is a close relation between the plant vascular system and the photosynthate translocation pathway (Li et al., 2000), an improved light intensity condition, promoting leaf photosynthetic capacity, could eventually contribute to enhanced dry mass production of tomato fruit (Li et al., 2000; Lu et al., 2012). But Higashide et al. (2015) also reported that although enhanced maximum photosynthesis rate was observed with elevated $\mathrm{CO}_{2}$ and fogging in cultivar 'Momotaro York', the fraction of dry matter distribution to fruit was significantly decreased. This indicated that improved light condition other than elevated $\mathrm{CO}_{2}$ and fogging would better enhanced sink strength of fruit. In addition, the strategy of periodic PD alteration was also land saving. Cultivating young and mature plants together making the ACPD of MB was as high as 16.27 plants $\cdot \mathrm{m}^{-2}$ (Fig. 6). This combined with the enhanced fruit yield of a single plant significantly enhanced the total yield in MB. The total soluble solids content determines fruit taste, which is an important index for commercial tomato quality analysis. Insufficient light can decrease the total soluble solids content of tomato fruit (Yanagi et al., 1995). In our experiment, the fruit in MB and F10 had significantly higher levels of soluble solids than F14.3 (Table 4), indicating a relatively smaller PD at the fruit development stage could increase the fruit soluble solids content. However, though there were dif- ferences in the ascorbic acid content and fruit hardness among treatments, the differences caused by PD changes were not significant. Previous research on the relationship between light irradiation and fruit ascorbic acid content has shown that ascorbate synthesis and metabolism in fruit are significantly affected by fruit irradiation in addition to leaf irradiation (Gautier et al., 2009). Additionally, the production of pectin and cellulose, which determine fruit hardness, in fruit cells is primarily controlled by the expression of genetic traits (Hadfield et al., 1998; Rose et al., 1997).

Additionally, the shading index which determines the periodically altered PD is determined by solar radiation. In the winter production season, due to frequent cloudy, snowy, or rainy days, $40 \%$ of the shading index was applied to maintain a similar irradiation condition to supplemental lighting (Lu et al., 2012). However, since solar radiation also affects the thermal environment, the plant growth rate and morphology may also undergo several stresses. For example, the thermal environmental factors in a greenhouse, such as temperature, humidity, and ventilation, will drastically change accompanied by continuous higher irradiation in the summer season, affecting the carbon assimilation rate. Therefore, the $40 \%$ value of the shading index, may be suitable only in winter because the source-sink balance and carbon assimilation rate in the high irradiation season were different. These results affect the plant growth rate and morphology, and this alteration indicated that the amount of light demand in the lower canopy would be different. From this view point, a fixed shading index of $40 \%$ may not be suitable for year-round tomato production. Further study on optimizing the shading index in different seasons is needed for higher economic benefit STTPS.

\section{Literature Cited}

Farquhar, G. D. and S. von Caemmerer. 1982. Modelling of photosynthetic response to environmental conditions. p. 549587. In: O. L. Lange, P. S. Nobel, C. B. Osmond and H. Ziegler (eds.). Physiological plant ecology II: Water Relations and Carbon Assimilation. Springer-Verlag, Berlin.

Farquhar, G. D., S. von Caemmerer and J. A. Berry. 1980. A biochemical model of photo-synthetic $\mathrm{CO}_{2}$ assimilation in leaves of C3 species. Planta 149: 78-90.

Fisher, D. F., G. A. Giacomelli and H. W. Janes. 1990. A system of intensive tomato production using ebb-flood benches. Prof. Hort. 4: 99-106.

Gautier, H., C. Massot, R. Stevens, S. Sérino and M. Génard. 2009. Regulation of tomato fruit ascorbate content is more highly dependent on fruit irradiance than leaf irradiance. Ann. Bot. 103: 495-504.

Giniger, M. S., R. J. McAvoy, G. A. Giacomelli and H. W. Janes. 1988. Computer simulation of a single truss tomato cropping system. Trans. ASAE 31: 1176-1179.

Govindasamy, R. 1996. A re-examination of supply response in the Northeastern fresh tomato market. New Jersey Agricultural Experiment Station, New Jersey.

Gunnlaugsson, E. and S. Adalsteinsson. 2006. Inter light and 
plant density in year-round production of tomato at northern latitudes. Acta Hortic. 711: 71-75.

Hadfield, K. A., J. K. C. Rose, D. S. Yaver, R. M. Berka and A. B. Bennett. 1998. Polygalacturonase gene expression in ripe melon fruit supports a role for polygalacturonase in ripening-associated pectin disassembly. Plant Physiol. 117: 363-373.

Heuvelink, E. and M. Dorais. 2005. Crop growth and yield. p. 81-144. In: E. Heuvelink (ed.). Tomatoes. CABI Publishing, Wallingford.

Higashide, T. and E. Heuvelink. 2009. Physiological and morphological changes over the past 50 years in yield components in tomato. J. Amer. Soc. Hort. Sci. 134: 460-465.

Higashide, T., K. Yasuba, T. Kuroyanagi and A. Nakano. 2015. Decreasing or non-decreasing allocation of dry matter to fruit in Japanese tomato cultivars in spite of the increase in total dry matter of plants by $\mathrm{CO}_{2}$ elevation and fogging. Hort. J. 84: 111-121.

Hovi, T., J. Nakkila and R. Tahvonen. 2004. Intra-canopy lighting improves production of year-round cucumber. Sci Hortic. 102: 283-294.

Janes, H. W. and R. J. McAvoy. 1989. Alternative greenhouse tomato production. The rutgers single-cluster system. Amer. Veg. Grow. 37: 14-16.

Janes, H. W. and R. J. McAvoy. 1991. Environmental control of a single-cluster greenhouse tomato crop. HortTechnology 1: $110-114$.

Kobayashi, S. 1997. A study on single-truss tomato production by hydroponics. I. Plant growth and fruit yield by different sowing dates over the year. J. Soc. Agr. Struc. Jpn. 27: 199-206 (In Japanese with English abstract).

Kobayashi, S. 1999. A study on single-truss tomato production by hydroponics. III. Effects of plant density and number of leaf above the truss on plant growth and fruit yield. J. Soc. Agr. Struc. Jpn. 30: 53-60 (In Japanese with English abstract).

Kozai, T. 2005. Closed systems for high quality transplants using minimum resources. p. 275-312. In: S. Gupta and Y. Ibaraki (eds.). Plant tissue culture engineering. Springer, Berlin.

Li, T., T. Seino, W. Ohkawa and K. Kanahama. 2000. Relation between the vascular system and photosynthate translocation pathways in tomato plants. J. Japan. Soc. Hort. Sci. 69: 6975 .

Logendra, L. S. and H. W. Janes. 1999. Hydroponics tomato production: Growing media requirements. Acta Hortic. 481: 483-486.

Lu, N., T. Maruo, M. Johkan, M. Hohjo, S. Tsukagoshi and Y. Ito. 2012. Effects of supplemental lighting within the canopy at different developing stages on tomato yield and quality of single-truss tomato plants grown at high density. Environ. Control Biol. 50: 1-11.

Matsuda, R., N. Ozawa and K. Fujiwara. 2014. Leaf photosynthe- sis, plant growth, and carbohydrate accumulation of tomato under different photoperiods and diurnal temperature differences. Sci. Hortic. 170: 150-158.

McAvoy, R. J. and H. W. Janes. 1988. Alternative production strategies for greenhouse tomatoes using supplemental lighting. Sci. Hortic. 35: 161-166.

McAvoy, R. J., H. W. Janes, B. L. Godfriaux, M. Secks, D. Duchai and W. K. Wittman. 1989. The effect of total available photosynthetic photon flux on single truss tomato growth and production. J. Hort. Sci. 64: 331-338.

Nakano, Y., H. Sasaki, A. Nakano, K. Suzuki and M. Takaichi. 2010. Growth and yield of tomato plants as influenced by nutrient application rates with quantitative control in the closed rockwool cultivation. J. Japan. Soc. Hort. Sci. 79: 4755 .

Okano, K., Y. Nakano and S. Watanabe. 2001. Single truss tomato system - a labor saving management system for tomato production. Japan. Agric. Res. Quart. 35: 177-184.

Pettersen, R. I., S. Torre and H. R. Gislerod. 2010. Effects of intera-canopy lighting on photosynthesis characteristics in cucumber. Sci. Hortic. 125: 77-81.

Rose, J. K. C., H. H. Lee and A. B. Bennett. 1997. Expression of a divergent expansin gene is fruit-specific and ripeningregulated. Proc. Natl. Acad. Sci. USA 94: 5955-5960.

Rousseaux, M. C., A. J. Hall and R. A. Sánchez. 1996. Far-red enrichment and photosynthetically active radiation level influence leaf senescence in field-grown sunflower. Physiol. Plant. 96: 217-224.

Scholberg, J., B. L. McNeal, J. W. Jonesb, K. J. Bootec, C. D. Stanleyd and T. A. Obrezae. 2000. Growth and canopy characteristics of field-grown tomato. Agron. J. 92: 152-159.

Sharkey, T. D. 1985. Photosynthesis in intact leaves of $\mathrm{C}_{3}$ plants: physics, physiology and rate limitations. Bot. Rev. 51: 53105.

Steinger, T., B. A. Roy and M. L. Stanton. 2003. Evolution in stressful environments II: adaptive value and costs of plasticity in response to low light in Sinapis arvensis. J. Evol. Biol. 16: 313-323.

Ting, K. C., G. A. Giacomelli and W. Fang. 1993. Decision support system for single truss tomato production. XXV CIOSTA-CIGR V Congress, Wageningen, Netherlands.

Trouwborst, G., J. Oosterkamp, S. W. Hogewoning, J. Harbinson and W. V. Ieperen. 2010. The response of light interception, photosynthesis and fruit yield of cucumber to LED-lighting within the canopy. Physiol. Plant. 138: 289-300.

von Caemmerer, S. 2000. Biochemical models of leaf photosynthesis. CSIRO Pub-lishing, Victoria.

Yanagi, T., E. Ueda, H. Sato, H. Hirai and Y. Oda. 1995. Effects of shading and fruit set order on fruit quality in single-truss tomato. J. Japan. Soc. Hort. Sci. 64: 291-297 (In Japanese with English abstract). 